\title{
The Challenge of Using Public Transport: Descriptions by People with Cognitive Functional Limitations
}

\author{
Jenny Rosenkvist \\ Lund University, Sweden ${ }^{\text {a }}$ \\ Kerstin Wendel \\ Lund University, Sweden
}

\author{
Ralf Risser \\ Lund University, Sweden \\ Agneta Ståhl \\ Lund University, Sweden
}

\author{
Susanne Iwarsson \\ Lund University, Sweden
}

\begin{abstract}
This paper describes the findings of a study aiming to achieve deeper insight into reasons people with cognitive functional limitations cease to use public transport. Semi-structured interviews in combination with a qualitative content analysis were performed with nine participants. The results showed that reasons not to use public transport were to some degree a usability problem — both real and imagined. Other reasons were that participants had changed from buses or trains to other modes of transport or had psychologically adapted themselves to a new situation which meant that they did not miss using public transport.
\end{abstract}

Keywords: Usability; Accessibility; Semi-structured interviews; Environment; Urban areas

\section{Introduction}

The accessibility of public transport for older people and people with functional limitations has been a subject of great interest during recent years (see Alsnih and Hensher 2003; CEMT 2004; Metz 2000). Increased interest in the international Conference on Mobility and Transport for Elderly and Disabled Persons (TRANSED 2007) is a sign of this change. However, the specific problems faced by people with cognitive functional limitations have not been sufficiently studied. Consequently, there is little knowledge about this group as users of public transport. In the study reported in this paper, an exploratory approach was taken in order to investigate major barriers to the use of public transport for this group. This research deals with the question of how people with cognitive functional limitations regard public transport and especially why they have stopped using it. This study was part of an ongoing interdisciplinary research project at Lund University in Sweden focused on accessibility in public transport for people with cognitive functional limitations.

\section{Background}

Planning for an accessible public transport system for all is a generally agreed necessity (CEMT 2004; Regeringens Proposition 1999/2000:79; SOU 2003:67) but at the same time it is a challenge. In Sweden, urban public transport is provided in a differentiated system to meet the den

${ }^{a}$ Jenny Rosenkvist, Department of Technology and Society, Lund University, Box 118, SE-22100 LUND, Swe- 
needs of various user groups. The system includes trunk route traffic for use by commuters; service route traffic with a higher level of service from the driver and shorter distances to bus stops for use by older people and people with functional limitations; and the Special Transport Service, which is a door-to-door service that can only be used by persons with special authorization (Svensson 2003). For a long time, both research and governmental evaluations in Sweden have emphasized the importance of the user perspective and the travel chain perspective when planning for various transport user groups (Olsson 2003; Ståhl 1997). However, both internationally and nationally, planning for accessibility to public transport predominantly focuses on people with visual or physical functional limitations (see Carlsson 2002; Davidsson 2001; Marin-Lemellet et al. 2001; Ståhl and Iwarsson 2007; Waara 2001), while the situation for people with cognitive functional limitations is generally overlooked (Davidsson 2001; Grönvall et al. 2004).

Cognitive functional limitations imply a more varied set of difficulties than physical functional limitations. Cognition can be defined as the "technique" the central nervous system uses to process information, which includes the ability to distinguish, organize and assimilate information. Brain injuries can cause difficulties in structuring and organizing information. Hence, people with cognitive functional limitations can have difficulties orienting themselves in time and space, solving problems, organizing, expressing themselves verbally, remembering, etc. Brain injuries can be innate or acquired, for example by a stroke. Often, people with cognitive functional limitations also have additional functional limitations such as physical or visual limitations (Abreu and Toglia 1987).

Accessibility is a concept describing the encounter between an individual's or a group's functional capacity and the design and demands of the physical environment (Iwarsson and Ståhl 2003). Defined in this way, the concept is based on the ecological theory of aging (Lawton and Nahemow 1973), meaning that the relationship between a person's functional capacity and environmental demands set both restrictions and possibilities for behavior. If one of these components changes, a balance can be maintained if one or more of the other components change as well (Lawton and Nahemow 1973). For instance, an individual's functional capacity can be altered due to a brain injury, leading to difficulties in understanding directional abstract concepts like North, South, East, and West. This can be compensated for by offering information that gives directions showing concrete significant landmarks in order to support the individual's need to orient themselves. (Hunter-Zaworski and Hron 1993).

While few recent studies have been published in this research field, some results elucidating the challenge of investigating the public transport situation for people with cognitive functional limitations have been presented. From a technical perspective, some reports have focused on barriers at transport terminals (McInery et al. 1992) and attempts have been made to specify operational guidelines, to give suggestions on technological changes, and to develop appropriate operational policies and training programs (Hunter-Zaworski and Hron 1993, 1999; Koppa et al. 1998). From a rehabilitation perspective, one case study demonstrated a step-by-step method for training people with brain injuries to start to use buses (Newbigging and Laskey 1995). Overall, most of the studies found are not up-to-date, meaning that they do not take into consideration the rapid technological development within the field of public transport that has taken place during recent years. In a more recent study, Logan et al. (2004) used semistructured interviews looking at attitudes and barriers for using transport in general among people who have had a stroke; their findings indicated that the use of public transport was 
experienced as difficult. In Europe, the MAPLE project 2003 emphasized that the needs of persons living with cognitive functional limitations are largely neglected because there is no systematic planning for users with cognitive functional limitations and the majority of transport providers in Europe have no operational definition for this group of users. Consequently, existing schemes and projects are scattered, and there is a lack of scientific knowledge on the current public transport situation for the user group targeted in this study.

\section{Aim of the study}

The aim of this study was to gain deeper insights into and understanding of the reasons behind the decision by people with cognitive functional limitations to cease using public transport.

\section{Method}

\subsection{Sample}

The participants were selected from a database created in another sub-study within the research project mentioned above. In the database, the individuals were taken from a national quality assessment register of stroke incidents (Riksstroke) at the Department of Neurology, Malmö University Hospital, Sweden. To be included in the database the individuals had to have had a stroke sometime between January 1st, 2002 and June 30, 2003; be able to move about independently, at least indoors, three months after their stroke; and live in ordinary housing three months after their stroke. Details of the sampling procedure are described in Wendel et al. (2008a). The database contains information from 84 individuals concerning their professionally evaluated and self-evaluated cognitive functional limitations, physical functional limitations, and use of mobility devices, depression symptoms, and activity performance. Cognitive functional limitations were professionally assessed by an experienced occupational therapist using Cognistat, a rapid and sensitive measure of cognition (Kiernan et al. 1987; Mueller et al. 2001).

Five major areas-language (three sub-sections); visual constructive skills; memory; calculation and reasoning (two sub-sections); and three general areas covering consciousness, orientation, and attention - within Cognistat were assessed. Each area or sub-section was scored as average, mild, moderate or severe impairment. Self-reported cognitive functional limitations were examined by a study-specific questionnaire containing 18 questions on cognitive tasks used in daily activities. It should correspond to the Cognistat, however, it was based on relevant literature, the International Classification of Functioning, Disability, and Health, (World Health Organization 2001) and the clinical experience of the authors (Wendel et al. 2008a). Data on physical functional limitations and the use of mobility devices were collected by means of the personal component in the Housing Enabler instrument (Iwarsson and Slaug 2001). Depression symptoms were self-rated by use of the Geriatric Depression Scale (Gottfries et al. 1997), where a score between six and 20 implied a depression. Activity performance (in-house, outdoor mobility, leisure/social activities, and work) was examined using the Frenchay Activity Index (FAI) (Dijkers et al. 2000; Turnbull et al. 2000). The FAI instrument was extended with questions about the modes of transport used and the use of telephones. Based on how frequently they used buses or trains after their strokes, the participants from the database were divided into subgroups; 14 individuals reported that since having a stroke they had ceased to 
travel by bus or train, while 41 individuals reported that, post-stroke, they continued to use buses or trains with reduced, unchanged, or increased frequency.

A strategic sampling strategy (Patton 1990) was used to select the participants for this study. The two basic criteria were that the participants had cognitive functional limitations and had been public transport travelers before the event that caused their cognitive functional limitations.

The 14 individuals not using buses or trains anymore fulfilled these criteria and were asked to participate. In addition, one individual who had reported continued use of public transport in the database was added to the 14 individuals not using buses or trains anymore, as this individual had ceased to use public transport at the time contact was made with the individuals inviting them to take part in the study. In the end, nine individuals agreed to participate in this study, and are hereafter referred to as the target group or the participants.

\section{Participants' characteristics}

The target group consisted of seven women and two men, aged from 45 to 90 . The two men lived with their spouses in apartments close to the city center. Five of the women lived alone in apartments, and the remaining two lived with their spouses in houses with gardens; one of them had children still living at home.

The target group exhibited a variety of types of cognitive functional limitations for each area and sub-section in Cognistat. However, regarding level of consciousness, all participants were judged as alert and none had memory or judgment difficulties (Table 1). Physical functional limitations - especially difficulty in bending and kneeling, and dependence on mobility devices-were present in the target group (Figure 1). The mobility devices included walking sticks or rollators (walking frames with wheels, handlebars with brakes, and in some cases a seat, basket or shelf). The use of walking aids appeared to be more common within the target group during the period in which this study was conducted than at the time data were originally entered into the database. Five of the participants had six or more symptoms of depression.

Table 1: Number of participants having professionally assessed cognitive functional limitations, divided into areas and sub-sections within Cognistat

\begin{tabular}{lccc}
\hline Area/sub-section in Cognistat & Mild & Moderate & Severe \\
\hline Orientation & 0 & 0 & 1 \\
Attention & 3 & 3 & 0 \\
Language/Comprehension & 2 & 3 & 0 \\
Language/Repetition & 1 & 1 & 0 \\
Language/Naming & 2 & 0 & 0 \\
Construction & 3 & 0 & 0 \\
Memory & 0 & 0 & 0 \\
Calculation & 1 & 0 & 1 \\
Reasoning/Similarities & 1 & 0 & 3 \\
Reasoning/Judgment & 0 & 0 & 0 \\
\hline
\end{tabular}

Assessed by means of the Cognistat instrument (Kiernan et al. 1987;

Mueller et al. 2001). 
Physical functional limitations and dependence on mobility devices

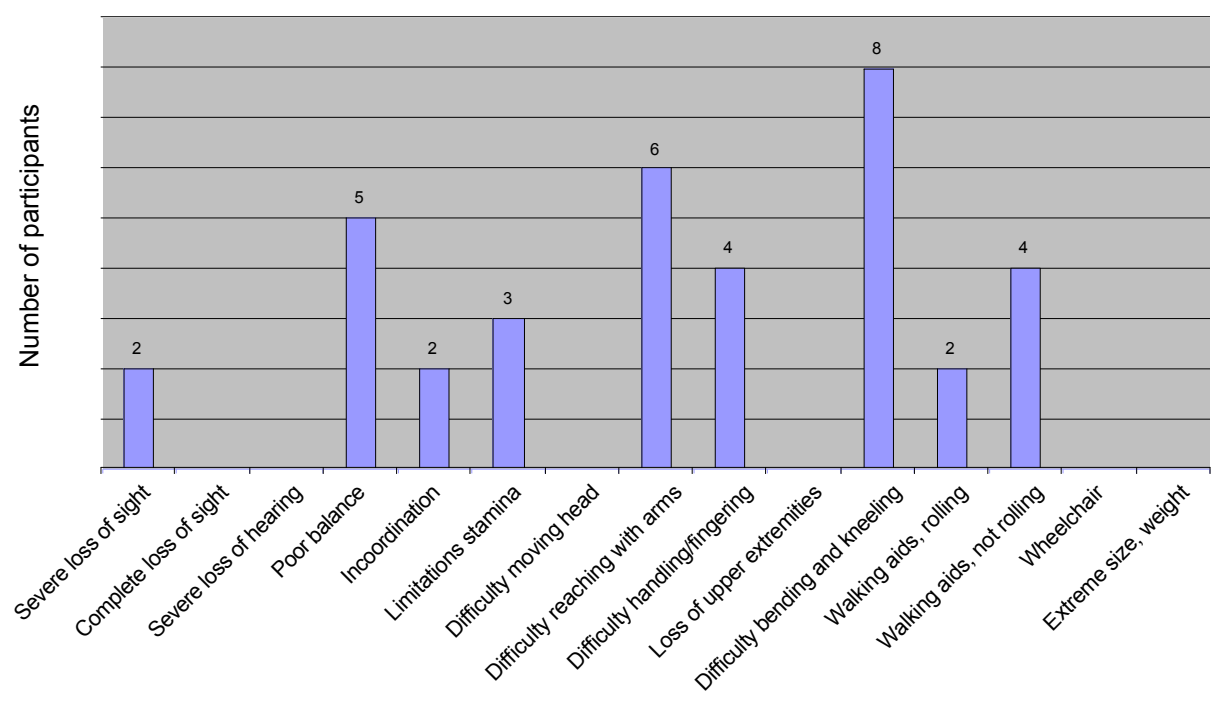

Figure 1: Description of participants' physical functional limitations and dependence on mobility devices. Data from the personal component of the Housing Enabler Instrument (Iwarsson and Slaug 2001).

\subsection{Study district}

The target group lived in Malmö, Sweden, or its environs. Malmö has an urban population of 270,000 and is the third largest city in Sweden. Most of the city area (82\%) is considered to be covered by public transport. In the central area the average distance to bus stops is 240 meters. The public transport system is differentiated, with fast trunk bus routes where buses run fast and often (every five minutes) to and from important destinations within the city, and local routes that take care of more restricted travel needs but which are not served as frequently (about every 30 minutes). So called "intermediate solutions," such as service route traffic or flex route traffic (Carlsson and Ståhl 2006) that are specifically designed to meet the needs of older people and people with functional limitations are not present in Malmö. The Special Transport Service (Svensson 2003) is provided for those who meet qualifications set by the municipality. When it comes to the design of the physical environment and the buses, more than half of the bus stops (56\%) are sheltered, and all buses are low-entrance buses, i.e. there are no steps up into the buses and the buses can kneel down to a height of $230 \mathrm{~mm}$.

\subsection{Semi-structured interviews}

The guide for the semi-structured interviews was developed on the basis of the results of another sub-study of the project (Rosenkvist et al. 2008) as well as on findings reported earlier by others (e.g. Hunter-Zaworski and Hron 1993, 1999; Koppa et al. 1998). The themes in the interview guides were:

- Mobility in general 
- Environmental factors that hinder or enable the use of public transport

- Strategies when desiring to use public transport

- Future use of public transport

- Ideal public transport

The question formulation was tested on several occasions, both within the project group and on persons not initiated into the project, before the interviews with the target group took place in order to avoid complicated words or phrases. The interviews were performed as conversations with open-ended questions about the themes described above. The intention was first of all to grasp the words of the participants. Starting out from open-ended questions, interviewers went on to encourage the participants to expand on their statements by the use of probing questions (Berg 2005). During the interview the answers were played back to the participants to ensure that the participants' own perspectives were understood, in order to strengthen credibility or internal validity (Persson 2006). The second theme, environmental factors that hinder or enable the use of public transport, was the most essential. Information given in one interview was taken into account and amended in the following interviews. The interviews were tape-recorded and transcribed.

\subsection{Procedure}

The first contact with the potential participants was by a telephone call during which the project was briefly presented and the person was asked to consider participation. This was followed up by a letter with extended information. About a week later, a second telephone contact was made to set a date for an interview. The interview was carried out in the participant's home by the first and fourth authors. During the visit the participant was asked to sign an agreement of consent, and the interviewers explained that the information gathered was to be treated as confidential. The repeated contacts with the participant before the interview were supposed to establish confidence between them and the interviewers. To establish confidence is important, especially for this group, as they, by experience, often hesitate to encounter new persons and events outside of their routine lives.

Both interviewers were present during all but one interview. The fourth author led the conversation, but as the interviewers represented different experiences together with people with cognitive functional limitations as well as different scientific fields, they both posed questions and encouraged the participants to describe their thoughts.

\subsection{Analysis}

When all interviews had been conducted, an open coding was performed in order to more systematically analyze the material. The codes were sorted and subsequently, in an iterative process, categories emerged. The participants' statements were units for analysis. For exemplification of the categories, individuals are quoted in the description of the results. In accordance with the qualitative approach, the analytical process introduced theoretical angles from which to view the results that were complimentary to the theories and conceptions that existed in the beginning of the study. 


\subsection{Ethical issues}

Before the interviews took place, the participants signed a consent agreement, and the information was treated confidentially. The design of the study had previously received approval from the regional ethical review board in Lund, Sweden.

\section{Results}

The interviews revealed that the participants' thoughts related to present and future use of public transport varied. Some had distanced themselves from the very thought, while others were prepared to consider using public transport now or at some time in the more distant future. The participants described what it would be like if they were to use public transport today, after having a stroke. The participants' descriptions of public transport originated, in some cases, from their imaginations or from what they had heard from friends or read in newspapers; in other cases, their descriptions originated from their experiences using public transport both before and after their strokes. There had been occasions when the participants had tested the use of public transport after having a stroke, together with friends or relatives, in order to see whether they could cope or not. However, the participants no longer viewed themselves as public transport users as they neither went by public transport on a daily basis, nor on their own, at the time of the interviews.

The core category emerging from the interviews is The use of public transport: A challenging activity either under consideration or out of the question. It comprises two main categories, each with two sub-categories: Future use of public transport is not a matter of course, and Environmental complexity and serial tasks challenge the use of public transport (see Figure 2).

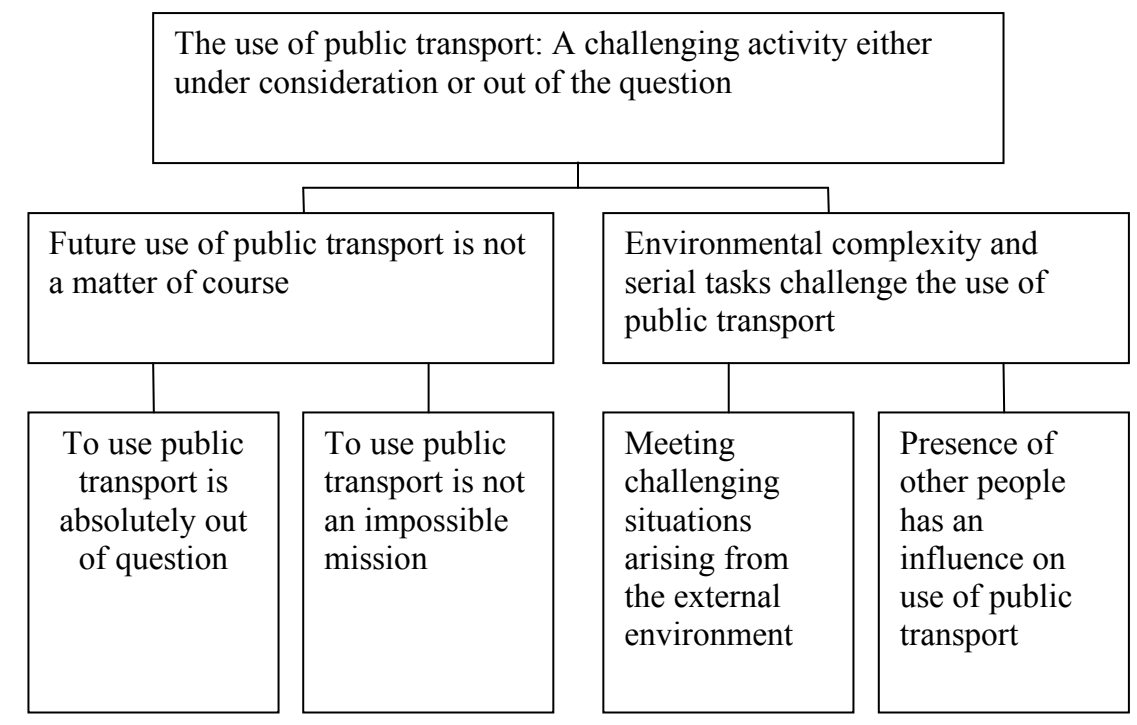

Figure 2: Categorization of the results from semi-structured interviews with people with cognitive functional limitations. 


\section{Future use of public transport is not a matter of course}

Some statements revealed that ideas of using public transport were far from the participants' minds-for example, one participant noted that she neither used it nor would like to. Other statements revealed that ideas of using public transport were present in the participants' minds. Two sub-categories appeared: To usepublic transport is absolutely out of question and To usepublic transport is not an impossible mission.

To use public transport is absolutely out of the question In the statements suggesting that the use of public transport was a distant thought in the participants' minds the use of public transport was described as an activity that belonged to the past or was considered as an activity the participants did not think about nor had to care about. One woman, who was very definite in her answer, emphasized that she did not want to think about activities that she did not judge herself able to manage. She stated that she became depressed when thinking about activities that she could not manage, such as using public transport. For her, it was better to be grateful for what she could do today than to think about activities that she could not perform. She had accepted, and was satisfied with, her situation as it was.

The interviews shed light on explanations of why using buses or trains might be completely out of the question. It could be due to the consequences of the stroke, which was exemplified by a woman who said that her loss of memory had made her forget how to use a buses and trains:

"the mere thought of leaving where we live and then all that traveling and then having to board the train [cleared her throat] oh, I don't know, I don't know anymore what you're supposed to do. I do not know how to handle objects. I have lost it all!"

In addition to stroke, reasons offered for not using public transport included cardiac illness, gout, and depression. One woman explained that she would not like to expose herself to the risk of being injured, should she try to use the bus, as that would worsen her depression. Other participants presented the decision to cease using public transport as a consequence of the aging process:

"No, no, I'll never do that again, old as I am, I don't believe any bus would take me on board, I'll be running on these legs before I ride [laughs]."

Further, participants reported that other modes of transport had replaced their need for buses or trains, for example by being entitled to use the Special Transport Service or by being transported by their children, friends or partners. One man stated that it was more natural to let his wife drive the car to one of the special parking spaces for the disabled, as they could then come closer to the entrance of their destination than they could by using public transport.

Some statements implied that the participants had tried to use buses and trains once or several times following their strokes. Those occasions were described as being "the straw that broke the camel's back" - experiences that had forced them make the final decision not to use public transport anymore. One woman said that she came to the conclusion that using the bus was no longer suitable for her following a tryout trip by bus with her daughter; she emphasized that her daughter, who she trusts highly, agreed with her. 
To use public transport is not an impossible mission In the statements suggesting that participants were willing to consider using public transport, it was described as an activity that the participants were able to manage to the same extent as they did before their strokes. The reasons cited by participants for not using public transport were not primarily focused on their own inability to do so, but rather on advice from other people, such as relatives who advised them not to use it. One example was a man who referred to what other people had told him about being neglectful. He meant that, due to his negligence, he might forget to look for cars coming from the left when standing at a pedestrian crossing. At the same time, he concluded that if he were to face such a situation, he would not be likely to forget to look for cars as he considered this to be too important to forget.

The statements that revealed thoughts about starting to use public transport again showed that public transport was still an issue about which the participants thought. One woman explained that she was prepared to make an attempt to use public transport again on her own, taking it one at a time. Her plan was to try the train by herself first, as taking the train was less stressful for her than taking a bus. Then, her daughter would meet her at the railway station and join her on the bus to their final destination. To start to take the bus from the railway station by herself would be a later mission. She explained that she was fighting uncomfortable feelings, such as stress, because travel by bus was not routine for her. However, if it were to become routine, she said that she would probably not be that nervous.

\section{Environmental complexity and serial tasks challenge the use of public transport}

The participants described their ideas of what it would be like if they were to use public transport today, as persons who had suffered a stroke. They described situations they considered challenging and explained how such situations affected them. This category comprised two sub-categories, namely Meeting challenging situations arising from the external environment and The presence of other people influences the use of public transport.

Meeting challenging situations arising from the external environment Participants stated that it was demanding to handle a complex external environment that presented situations in which a series of tasks had to be performed quickly. An example was the situation that arises when getting on and off a bus, which includes standing in a queue, managing the payment process, finding a seat, and in some cases bringing a rollator on board. One woman described this situation:

"I can't board with my rollator and I can't put the rollator aside and go up front and pay and then go back and find a seat, because you can't sit on your rollator because you'll fall off."

A male participant pointed out the difficulty of performing a series of tasks in a short time, even though he was able to perform them one by one:

Participant: "I can manage the step up into the bus, but I don't get more than halfway before he starts driving."

Interviewer: "No way?!" 
Participant: "I can't take out the....what do you call it...the ticket and then pay when there's a queue and then find a place to sit. Plain impossible when I'm on my own. But, if my wife is along, then she takes care of the fare."

He explained that the complex situation, the need to perform a series of tasks, and time pressure made his experience very stressful (he was almost seized by panic) when trying to get off the bus. However, if his wife assisted him and when he only had to handle a few tasks by himself, one at a time, he found it much easier.

According to the statements, the bus was generally regarded as being a greater challenge than the train. It was noted that on a bus it is the passenger's responsibility to know where to get off and when to communicate that to the driver. This was exemplified by one woman who considered this a problem because she was unsure about when and where to push the stop button in order to make the bus stop. She felt that it would be easier to use the train, as the train comes to a standstill at every designated stop, which diminished the risk of getting off at the wrong station.

Further, the statements revealed that challenging situations could be caused by the design of the physical environment, such as differences in level which can be especially difficult when using a rollator:

\section{"Stairs are simply simply not suitable for people with rollators."}

A rollator was the mobility aid for several of the participants, therefore it was considered to be easier to use buses or trains if the step onto the bus or train was at the same level as the edge of the pavement or platform.

Finally, some statements implied that the participants were not able to point out specific situations that they considered themselves unable to handle. Rather, the statements demonstrated a general fear and anxiety about "everything" related to using buses and trains. One woman described it as a blurred anxiety-everything scared her. She said that, for example, technical aids would not encourage her to use the bus because she was afraid, anxious and worried at the very thought of crossing the street to get to the bus stop. It was not the lack of practical help in managing environmental conditions that made her hesitate to use public transport, but rather her negative feelings.

Presence of other people influences the use of public transport The particpants' statements made it obvious that their use of public transport was influenced by the presence of other people. For example, participants stated that they did not want to disturb or irritate other passengers, nor would they want to be disturbed by others. They explained that they needed additional time to perform various tasks in situations such as getting onto or off of a bus, and were concerned that they might impede other passengers who were in a hurry. In order to avoid situations where they believed they might disturb others, participants considered using public transport during nonpeak hours if possible. One man even thought that older people and people with functional limitations should arrange their transport in such a way that they would not be a hindrance for other public transport users, for example by using other modes of transport more suitable to individuals with functional limitations.

The statements also revealed that trust in other people was an important issue. For example, one woman said that it was no problem for her to move about in her neighborhood because she 
knew that there were people there in whom she could trust. Local people she knew would be there to help if anything should happen to her, as they knew of her cognitive functional limitations. Other participants had different experiences, namely that people out on the streets do not offer help if one falls. One participant talked about how he fell on the pavement and everybody passed by without assisting him. As a consequence he no longer expects that people will offer their help if he should fall in a public place.

According to the participants' statements, the availability of other people to help implies safety and support when it is time to leave the home environment. These other people may include partners, friends, or drivers from the Special Transport Service who come to pick up participants at their homes. The participants noted that they could be sure of receiving personal support when using the Special Transport Service or taxis, but they did not feel sure of such support when using buses where the driver has too many things to do at the same time. It was also mentioned that an accompanying person would most likely have insight into the participant's problems and would be prepared to help when assistance was needed, for example by being prepared to catch the participants if they were about to fall. However, some did not wish to be accompanied when leaving home. For instance, one woman said that she preferred to do things on her own, because then she could take her time without being a hindrance to others. She explained that she had become more careless than before her stroke; nowadays, she also needed more time to manage things and for that reason she preferred to be alone.

\section{Discussion}

In line with the aim of this article, the results presented contribute to a deeper insight into and understanding of persons affected by cognitive functional limitations following a stroke who decide to cease using public transport.

The participants' concerns about challenging situations when using public transport reflected their thoughts around their individual competence in relation to environmental pressure (Lawton and Nahemow 1973) in public transport situations. They described situations in which environmental pressure exceeded their individual competence. With this in mind, one can assume that the findings indicated accessibility problems within public transport-or, more specifically, that the findings indicated usability problems (Iwarsson and Ståhl 2003), as the results reflected the participants' subjective evaluations of how the environment restricted their performing an activity in a specific environment. One example of a usability problem was the participants' description of how a complex external environment and the necessity of performing a series of tasks rapidly affected their performance when getting onto buses. However, using buses or trains was an activity that was no longer a part of the participants' everyday lives, a fact that was shown by statements in which participants' descriptions originated from their earlier experiences of boarding a bus before they suffered strokes. Consequently, they described usability from the perspective of a person not living with cognitive functional limitations. On the other hand, the situations that the participants mentioned must have had a certain meaning for them since their awareness of them had increased (Steinfeld and Danford 1999). Even if they do not constitute usability problems in the "actual" environment, but rather in the participants' minds, the environmental pressure was thought of as being too high, so the idea itself was a hindrance for them. 
The presence of specific other individuals, such as friends or individuals who the participants trusted, was experienced as supportive when using public transport. This finding implies that the participants wanted to know that there were people in the public environment and the public transport system who understood their cognitive functional limitations and could give proper assistance. This finding is supported by results from a previous study (Hunter-Zaworski and Hron 1993) concluding that personal interaction was more effective than technical solutions in assisting persons with cognitive functional limitations, because it included the possibility of flexible assistance in unique situations. In addition, previous studies concluded that one way to provide opportunities for interaction was to reduce the number of tasks that drivers were required to perform, a point which was also touched upon by the participants in this study.

The findings of this study on user perspectives complement the results of Rosenkvist et al. (2008), which describes experts' perspectives on prerequisites for mobility for the target group. The experts emphasized the importance of the travel-chain perspective, which was also touched upon by the woman in this study who said that the mere thought of crossing the street to the bus stop was a hindrance for her. The travel-chain perspective stresses the importance of not separating the time spent on board the vehicle from the other parts of the journey, such as the search for information regarding transport possibilities, travel to and from the vehicle, changes at terminals, etc. If one link in the chain is missing, the whole chain will be broken (Ståhl 1997).

The finding that the participants would avoid using buses during peak travel periods in order not to disturb other passengers implied that the participants' behavior was a result of an interaction with their environment. From the interaction perspective, people resign themselves to their environment most of the time, but if environmental demands exceed an individual's level of tolerance, their will to make a change in their situation increases. For example, they may make changes in their own environment by moving to another area, or they may adjust themselves to the new situation psychologically by altering their expectations and values (Steinfeld and Danford 1999). The findings of this study revealed that it was preferable to use modes of transport where pressure from other passengers could be avoided and where assistance was available from the driver. Those statements implied that there is a demand for intermediate solutions of public transport, such as service route traffic or Special Transport Service where the environmental pressures are lower (Ståhl 1997). Consequently, the participants who had replaced their use of buses and trains by the use of other modes of transport, such as the Special Transport Service, can be interpreted as having changed their environment in order to be able to deal with the environment in a proper manner. The participants' statements based on experiences with public transport before having a stroke can be interpreted as a psychological adjustment that protects them from psychological dissonance (Festinger 1962) that could be caused by thoughts of using public transport and not being able to do so. Because people strive to avoid psychological dissonance, the participants avoided thinking about public transport, as to do so would increase psychological dissonance. This is understandable in the light of the findings in a study of people's use of public transport after a stroke, which showed that individuals who reduced their use of public transport or eliminated it entirely had more professionally assessed and self-reported cognitive functional limitations than individuals who continued to use public transport (Wendel et al. 2008b). In addition, the study showed that these individuals were less frequently involved in social activities outside of their homes than individuals whose pattern of public transport use was unchanged. It is possible to conclude that the target group 
in the current study, experiencing cognitive functional limitations and activity restrictions, preferred to avoid thinking about public transport in order to avoid psychological dissonance.

As this is a rather novel field of research for traffic planners, there is no certain method available that is well-adapted for studying the public transport situation for those with cognitive functional limitations. The decision to approach the field of research by focusing the ex-users' reasons for not using public transport by means of qualitative interviews proved advantageous. When evaluating the statements given by the participants, it is important to emphasize that they reflected the participants' thoughts and ideas about using public transport. The descriptions of usability problems might not directly apply to the "actual" environment, but they might be considered as usability problems in the participants' minds. The statements range from realistic to imaginative, as the participants' descriptions originated both from their imaginations and from experiences of actual journeys.

\section{Summary and prospects}

This effort to understand the decisions of people with cognitive functional limitations resulting from stroke to cease using public transport yielded a picture of a group for whom using public transport, in some cases, involved greater demands than they could handle. This was especially true when the environment was characterized by serial tasks and high complexity. Further, within the target group, there were those who had adapted their environment or themselves to new conditions. Reasons for not using buses or trains were, in those cases, that these modes had been exchanged for other modes of transport, such as traveling by with relatives or using the Special Transport Service; alternatively, some participants' responses indicated that they had psychologically adapted to a sedentary situation, for example, saying that their decision to cease using public transport was due to the fact that they were now elderly. One way to better enable the use of public transport for this group would be to make sure that the whole travelchain works throughout and that the personne lworking on buses or trains possess sufficient knowledge of cognitive functional limitations to be able to show understanding and patience when in contact with individuals in this group. However, a more important finding was that in some cases it was not the "actual" environment that constituted a hindrance, but rather the participants' ideas. Consequently, in a planning process, the findings of this study may not be a basis for redesigning the public transport environment as such. Nevertheless, the results may constitute a basis for designing information and education material directed towards people with cognitive functional limitations showing them how to use public transport-an area that earlier studies have identified as particularly important (Hunter-Zaworski and Hron 1993).

The results of this study constitute a rich basis for further studies on the situation in public transport for people living with cognitive functional limitations. In further studies, the implications for usability issues must be investigated by observations in real environments, connected to interviews with the individuals observed. However, for those in this group who are inclined to start using public transport again after suffering a stroke, the findings of this study are valuable for understanding under what conditions public transport can be brought within reach again. They can help to point out implications on usability issues that are thought of as being a hindrance. 


\section{Acknowledgments}

This paper was based on data from the project "Accessibility in public transport for people with cognitive impairments-Survey, methodological development and innovative IT-solutions," funded by the Swedish Governmental Agency for Innovation Systems (20011 - 06707), the Swedish Road Administration (AL90B 2002:7609), the Swedish Rail Administration (S033608/AL50), and the Swedish Council for Working Life and Social Research (2002-0931). The authors thank all consortium members at Lund University for their contribution; in particular, thanks are extended to Jarl Risberg, Prof. Em.

Further, this paper was prepared within the Center for Aging and Supportive Environments (CASE), at Lund University, financed by the Swedish Council for Working Life and Social Research.

\section{References}

Abreu, B. and J. Toglia. 1987. Cognitive rehabilitation: A model for occupational therapy. The American Journal of Occupational Therapy 41 (7): 431-438.

Alsnih, R. and D. Hensher. 2003. The mobility and accessibility expectations of seniors in an aging population. Transportation Research Part A 37 (10): 903-916. doi:10.1016/ S0965-8564(03)00073-9.

Berg, B. 2005. Qualitative Research Methods for the Social Sciences. Allyn and Bacon, 5 edition. Carlsson, G. 2002. Catching the bus in old age. Methodological Aspects of Accessibility Assessments in Public Transport. Lund: Studentlitteratur.

Carlsson, G. and A. Ståhl. 2006. Hur används servicelinjer och flextrafik? Resvanor och attityder bland boende och resenärer. [English title: The use of Service Routes and Flex Traffic. Travel Habits and Attitudes among Residents and Travellers]. Bulletin 230, Lund Institute of Technology, Department of Traffic Planning and Engineering.

CEMT. 2004. Improving Accessibility of Transport. Implementation at the National Level of Measures to Improve Accessibility. Conclusions and Recommendations. Technical Report CEMT/CM(2004)13, European Conference of Ministers of Transport Council of Ministers. URL http://www.internationaltransportforum.org/europe/ecmt/cm/pdf/ CM200413e.pdf.

Davidsson, G. 2001. Funktionshindrades resvanor. Statistics Sweden.

Dijkers, M., G. Whiteneck, and R. El-Jaroudi. 2000. Measures of social outcomes in disability research. Archives of Physical Medicine and Rebabilitation 81 (12 Suppl 2): 63-80. doi: 10.1053/apmr.2000.20627.

Festinger, L. 1962. A Theory of Cognitive Dissonance. Stanford University Press.

Gottfries, G., S. Noltorp, and N. Norgaard. 1997. Experience with a Swedish version of the Geriatric Depression Scale in primary care centres. International Journal of Geriatric Psychiatry 12 (10): 029-34. doi:10.1002/(SICI)1099-1166(199710)12:10<1029:: AID-GPS683>3.0.CO;2-D.

Grönvall, O., A. Ståhl, and S. Iwarsson. 2004. Can people with cognitive functional impairment use public transportation? A sub-study of conditions in Sweden for the EU project MAPLE, Improving Mobility and Accessibility for People with Learning Diffculties in Europe. Technical Report VS/2003/0444, Lund University, Department of Technology and Society. 
Hunter-Zaworski, K. and M. Hron. 1993. Improving Bus Accessibility for Persons with Sensory and Cognitive Impairments. Final Report DOT-T-94-04, US Department of Transport, Federal Transit Administration, Washington DC.

- - 1999. Bus accessibility for people with cognitive disabilities. Transport Research Record 1671: $34-39$.

Iwarsson, S. and B. Slaug. 2001. The Housing Enabler. An Instrument for Assessing an Analysing Accessibility Problems in Housing. Veten \& Skapen HB \& Slaug Data Management, Nävlinge and Staffanstorp, Sweden.

Iwarsson, S. and A. Ståhl. 2003. Accessibility, usability and universal design - positioning and definition of concepts describing person-environment relationships. Disability and Rehabilitation 25 (2): 57-66.

Kiernan, R., J. Mueller, J. Langston, and C. V. Dyke. 1987. The neurobehavioral cognitive status examination: A brief but differentiated approach to cognitive assenssment. Annals of Internal Medicine 107: 481-485.

Koppa, R., B. Davies, and K. Rodriguez. 1998. Barriers to Use of Transportation Alternatives by People with Disabilities. Technical Report SWUTC/98/467402-1, Texas Transportation Institute. URL http://swutc.tamu.edu/publications/technicalreports/467402-1.pdf.

Lawton, M. and L. Nahemow. 1973. Ecology and the aging process. In L. M. Eisdorfer C, ed., The psychology of adult development. Washington: American Psychological Association.

Logan, P., J. Dyas, and J. Gladman. 2004. Using an interview study of transport use by people who have had a stroke to inform rehabilitation. Clinical Rehabilitation 18: 703-708. doi: 10.1191/0269215504cr742oa.

MAPLE Project. 2003. Improving mobility and access for people with cognitive impairments. Technical report, European Commission DG for Employment, Social Affairs, and Equal Opportunities. URL http://www.maple-eu.com/Reports/MAPLE-pages.pdf.

Marin-Lemellet, C., G. Pachiaudi, and B. LeBreton-Gadegbeku. 2001. Information and orientation needs of blind and partially sighted people in public transportation: Biovam project. Transportation Research Record 1779: 203-208. doi:10.3141/1779-27.

McInery, P., B. Barkow, and L. Suen. 1992. Travel difficulties related to vision, hearing and cognitive/emotional disability. In Comotred 92 Mobility and transport for elderly and disabled persons, Proceedings of the 6th International Conference. Lyon: eurexpo.

Metz, D. 2000. Mobility of older people and their quality of life. Transport Policy 7: 149-152. doi:10.1016/S0967-070X(00)00004-4.

Mueller, J., R. Kiernan, and W. Langstone. 2001. COGNISTAT (The Neurobehavioral Cognitive Status Examination). The Northern California Neurobehavioral Group, Inc., 5 edition.

Newbigging, E. and J. Laskey. 1995. Riding the bus: teaching an adult with brain injury to use a transit system to travel independently to and from work. Brain Injury 10 (7): 543-550.

Olsson, A. 2003. Hela Resan - en nödvändighet för att nå målet om tillgänglig kollektivtrafik àr 2010: Slutrapport i projektet Hela Resan. Technical report. URL http://www.rikstrafiken. se/db_dokument/Slutrapport_helaresan_ny.pdf.

Patton, M. 1990. Qualitative evaluation and research methods. Newbury Park, Ca.: Sage.

Persson, R. 2006. Pragmatisk analys: att skriva om och tolka kvalitativa data. ISBN 978-184728-014-5.

Regeringens Proposition. 1999/2000:79. Frä patient till medborgare - en nationell handlingsplan för handikappolitiken. Stockholm: Socialdepartementet. 
Rosenkvist, J., R. Risser, S. Iwarsson, and A. Ståhl. 2008. A picture of mobility among people with cognitive functional limitations, drawn by experts. Submitted.

SOU. 2003:67. Kollektivtrafik med människan i centrum: Betänkande från kollektivtrafikkommittén.

Ståhl, A. 1997. Äldres och funktionshindrades behov i kollektivtrafiken: Probleminventering och nulägesbeskrivning. Bulletin 148, Lund Institute of Technology, Department of Traffic Planning and Engineering.

Ståhl, A. and S. Iwarsson. 2007. Tillgänglighet, säkerhet och trygghet för äldre i den lokala miljön. Demonstrationsprojektet Kom så gär vi. [English version: Accessibility, safety and security for older persons in the local outdoor environment: The demonstration project "Let's go for a walk"]. Final report 2007:109, Vägverket Region Skåne, Kristianstad.

Steinfeld, E. and G. Danford. 1999. Theory as a basis for research on enabling environments. In D. G. Steinfeld E, ed., Enabling Environments. Measuring the Impact of Environment on Disability and Rehabilitation. New York: Plenum.

Svensson, H. 2003. The Public Transport Preferences of Elderly People: A Study Related to Individual Capacity and Environmental Stress in Service Route Traffic and Other Systems. Ph.D. thesis, Department of Technology and Society, Lund Technical University, Lund, Sweden.

TRANSED. 2007. Transed the international conference on mobility and transport for elderly and disabled persons. URL http://www.tc.gc.ca/Transed2007/.

Turnbull, J., P. Kersten, M. Habib, L. McLellan, M. Mullee, and S. George. 2000. Validation of the frenchay activities index in a general population aged 16 years and older. Archives of Physical Medicine and Rehabilitation 81 (8): 1034-8. doi:10.1053/apmr.2000.7162.

Waara, N. 2001. The Need of Information in Public Transport-Elderly and Disabled Persons Pre-Journey Travel Information Requirements. Licentiate thesis, Department of Technology and Society, Lund Technical University, Lund, Sweden. Bulletin 206.

Wendel, K., J. Risberg, H. Pessah-Rasmussen, A. Ståhl, and S. Iwarsson. 2008a. Long-term cognitive functional limitations post-stroke: Objective assessment compared to self-evaluations and spouse reports. International Journal of Rehabilitation Research 31 (3): 231-9.

Wendel, K., A. Ståhl, J. Risberg, H. Pessah-Rasmussen, and S. Iwarsson. 2008b. Post-stroke functional limitations and changes in use of mode of transport.

World Health Organization. 2001. International Classification of Functioning, Disability and Health (ICF). URL http://www.who.int/. 